\title{
Promoting condom usage to male sex workers in Thailand: A development of a conceptual framework: Social Marketing Perspective
}

\begin{abstract}
Thailand's booming tourism sector significantly contributes to the country's economy. Sex tourism is also popular in Thailand, where male sex workers are more at risk to HIV threats than their female counterparts. Social marketing campaigns have been useful in addressing several problematic behaviours, such as smoking, binge drinking, unprotected sex and unhealthy dietary practices. Hence, the main purpose of this research study is to propose a conceptual framework for promoting safe sex practices to male sex workers in Thailand. The Theory of Planned Behaviour (TPB) has been generally applied to help understand and examine behavioural change intentions, and develop behavioural change initiatives. TPB attempts to identify the psychological determinants of behavioural change intention in a single point of time. However, it does not show how behavioural change occurs as a process, or at various stages. As this theory is not adequate for understanding the entire process of behavioural change, a more comprehensive theoretical framework is required. Combining the Theory of Planned Behaviour with the Stages of Change Theory (SCT) provides a highly comprehensive theoretical framework. The Stages of Change Theory is used in the social marketing field to facilitate behavioural change. SCT shows the behaviour change as a process. The implications of this new framework for both theory and practice are discussed, as well as the directions for future research, which would be of use to researchers and practitioners in the social marketing field.
\end{abstract}

\section{Keywords}

the stages of change theory, the theory of planned behaviour, Thailand, condom use 


\section{Introduction}

Thailand is a newly industrialised country with a large tourism industry and popular tourist destinations, such as Pattaya, Bangkok, Phuket and Chiang Mai. Tourism plays a significant part in the Thai economy, constituting approximately 6.7\% of Thailand's GDP (Bangkok Post, 2012). The number of international tourists per year has increased from around 330,000 in 1967 (Ouyyanont, 2001) to over 22 million in 2012 (Bangkok Post, 2012). Thailand is well known for sex tourism, which plays a significant part in the Thai tourism industry. As a result, HIV/AIDS has become a health risk in Thailand especially among sex workers (Australian Broadcasting Corporation, 2013). For example, in 2011, 17.7\% male sex workers in Thailand were reported to have been infected by HIV which is the highest HIV rate among male sex workers in South East Asian region (UNGASS, 2012).

Social marketing campaigns have been successful in addressing many problematic behaviours, such as smoking and unprotected sex (Hastings, 2007; Peattie \& Peattie, 2009). Thus, these campaigns can be effective in addressing unprotected sexual activities in this context. Social marketing initiatives focus on changing behaviour to further the wellbeing of individuals and the society at large (Peattie \& Peattie, 2009). Donovan and Henley (2010) define social marketing as "the application of commercial marketing technologies to the analysis, planning, execution and evaluation of programs designed to influence the voluntary or involuntary behaviour of target audiences in order to improve the welfare of individuals and society” (p 6). Therefore, based on social marketing techniques and theories, a conceptual framework is proposed for encouraging condom usage and safe sex practices to male sex workers in the popular tourist destinations of Thailand. 


\section{Literature review}

\subsection{Thai experience relating to sex industry, condom usage and male sex workers}

In Thailand, the services of sex workers are often available in both direct and indirect establishments (United Nations Programme on HIV/AIDS, 2000). Direct establishments include brothels or hotels, whereas indirect establishments encompass clubs, bars, karaoke bars, gay bars, massage parlours, cafes and restaurants (Ford \& Koetsawang, 1999). Both male and female sex workers provide services in these establishments. Male sex workers provide a variety of sexual services to their clients, such as mutual masturbation, topping (insertive anal intercourse), receptive oral sex, bottoming (receptive anal intercourse), vaginal oral sex and rimming (oral-anal sex) (Guadamuz et al., 2010). Various initiatives have been carried out by several bodies, including international non-governmental organisations and the Thai Ministry of Public Health, with the aim of protecting sex workers from HIV and sexually transmitted diseases. Such initiatives include: awareness campaigns targeting both the owners of commercial sex places and their sex workers; free medical clinics organised periodically; free condoms distributed in places where commercial sex was available; and an increased supply of condoms to meet demand (United Nations Programme on HIV/AIDS, 2000). In particular, condom usage among male sex workers is comparatively lower than that among female sex workers (Chemnasiri et al., 2010). Janepanish, Dancy, and Park (2011) indicate that HIV/AIDS is the leading cause of death for Thai males.

There have been various barriers to adopting condom usage in Thailand. The main barrier to successfully implementing condom usage is that many clients do not like to use condoms. They believe that using condoms will reduce sexual pleasure, so they prefer to go to places that allow them to have sex without condoms (Fontanet et al., 1998). Clients and sexual partners pressurize them to not use condoms, as a result sex workers often suffer from a lack of 
bargaining power. Sex workers have less capacity and a lack of negotiation skills to convince their clients to use condoms which affect condom usage in Thailand. Sex workers' knowledge of sexually transmitted diseases including HIV threat is limited (Buckingham, Moraros, Bird, Meister, \& Webb, 2005; Wawer, Podhisita, Kanungsukkasem, Pramualratana, \& McNamara, 1996). There is also a lack of coordination among the law enforcement authorities in successfully encouraging condom adaptation among sex workers in Thailand (United Nations Programme on HIV/AIDS, 2000).

With comparatively less attention than female sex workers, Thai male sex workers remain an under-studied segment (Guadamuz et al., 2010). Although research studies have been carried out on condom usage among Thai sex workers, and particularly on male sex workers (Guadamuz et al., 2010; Janepanish et al., 2011; Toledo et al., 2010), theoretically sound research studies are still lacking (Guadamuz et al., 2010; Janepanish et al., 2011). Therefore, this study is aimed at proposing a sound conceptual model which will be useful in designing a theoretically-based intervention program.

\subsection{The Theory of Planned Behaviour and condom usage}

Researchers have predominantly used the Theory of Planned Behaviour to understand behavioural change (Chatzisarantis \& Hagger, 2005; McEachan, Conner, Taylor, \& Lawton, 2011; Sniehotta, 2009). The Theory of Planned Behaviour (TPB) developed by Ajzen and Fishbein (1980) and Ajzen (1991), posits that an individual's intention at any given point of time and context would be a predictor of their behaviour. They considered attitudes towards behaviour, subjective norms and perceived behavioural control (PBC), the antecedents of behavioural intentions. The TPB is useful for understanding the effects of attitudes, subjective norms and perceived behavioural control on behavioural intention (McEachan et al., 2011). 
Several researchers have used the TPB to investigate condom use and safe sex behaviour among sex workers, teens and youth (Carmack \& Lewis-Moss, 2009; Mausbach, Semple, Strathdee \& Patterson, 2009; Schaalma et al., 2009). These researchers further suggest positive perceptions, attitudes and beliefs towards safe sex practices determine condom use among sex workers, teens and youth. Their confidence in using condoms, and their ability and skills to obtain condoms and to negotiate condom use with sexual partners and customers, also determine their intentions to use condoms. Social structure and perceptions of others, particularly those of other sex workers, influence sex workers' intentions to use condoms. That is, whether fellow sex workers, peers, industry, employers, sexual partners and customers, accept or not accept condom use, determine condom usage during sexual intercourse. This discussion indicates that the three antecedents suggested in the TPB- attitudes, perceived behavioural control and subjective norms (discussed in the previous paragraph) - determine the intentions to use condoms.

\subsection{Criticisms of using the TPB for understanding behavioural change}

Although the TPB is useful in understanding individuals' intentions to give up problematic behaviours, such as unprotected sex, it lacks clarity in designing intervention programs targeting at behavioural change. That is, since the TPB does not show the entire process of behavioural change in its own right (Sniehotta, 2009), the theory does not demonstrate how to derive a behavioural change. Furthermore, the TPB does not show the process subsequent to the formation of behavioural intention (Sniehotta, 2009). The shortcomings of applying this theory are expanded on below.

Behavioural change is a process rather than a one-point-in-time intention (McEachan et al., 2011). It is a process consisting of acquiring knowledge of that behaviour, forming attitudes, developing intentions, and progressing through nascent and mature behavioural adaptations. 
However, the TPB does not consider the influence of knowledge on behavioural intention research, which is a shortcoming of this theory (Sniehotta, 2009; Sniehotta, Presseau, \& Araújo-Soares, 2014). Nor does the TPB show the process subsequent to the formation of behavioural intention. After forming the intention to change a behaviour, people can progress from a nascent stage to a mature stage with regards to implementing the adopted behaviour, which is not emphasized by the TPB (McEachan et al., 2011; Sniehotta et al., 2014). Because of these shortcomings, the TPB provides limited practical guidance for nurturing behavioural change.

These shortcomings have also been identified in studies relating to safe sex practices. It has been suggested that a lack of knowledge of safe sex practices, condom usage, and the consequences of unprotected sex (HIV threat and sexually transmitted diseases), negatively affects the intentions to use condoms (Ananth \& Koopman, 2003; Garcia-Retamero \& Cokely, 2011). A poor knowledge of these issues also reduces interests and desires in using condoms. Therefore, researchers have suggested incorporating the knowledge as an essential component into the model predicting the adoption of condom usage (Ananth \& Koopman, 2003; GarciaRetamero \& Cokely, 2011). They remark that efforts should be made to organise awareness campaigns and educational programs. In addition, educational materials and brochures promoting condom usage need to be made available to those who are vulnerable to unprotected sexual practices. This will enhance positive attitudes, favourable norms, confidence and intentions relating to condom usage ( $\mathrm{Gu}$ et al., 2009). This discussion underlines the importance of adding knowledge to a TPB-based behavioural change framework.

Therefore, an alternative and more insightful theoretical framework is required to explain behavioural change. Montano and Kasprzyk (2008) suggest that the TPB needs to be combined with another theory that considers the influence of knowledge on behavioural development. 
Similarly, Sniehotta (2009) suggests that the TPB can be combined with a complementary theory to create a comprehensive understanding of behavioural change. That is, in addition to attitudes, perceived behavioural control, subjective norms and intentions relating to a new behaviour (desirable behaviour), the antecedent and subsequent events, or stages, associated with behavioural change need to be explained by a theoretical framework. Such a framework would also provide better practical guidance for encouraging behavioural change, such as protected sex. This study combines the TPB with the Stages of Change Theory (SCT) to provide an integrated theoretical framework in developing pro-condom usage behaviour among Thai male sex workers. To this end, scholars who investigated HIV, condom usage and safe sex practices, also suggest that TPB and SCT can be combined to derive a better framework to promote condom usage (Arden \& Armitage, 2008; Armitage \& Talibudeen, 2010; Evans \& Lambert, 2008). Although they have made this suggestion, the extant literature does not provide such a framework. This study fills this gap in the literature, attempting to combine both TPB and SCT to develop an alternative and comprehensive framework that enhances condom usage. Both these theories have a few shortcomings, however a combined application of these theories would better assist in overcoming theses weaknesses. That is, the strengths of one theory can offset the weaknesses of another theory. This has been explained in the section titled "2.6 The rationale of combining both TPB and SCT". In the following sections, the development of a comprehensive framework has been articulated in a detailed and logical manner.

\subsection{The Stages of Change Theory (SCT)}

Social marketing researchers and practitioners apply the Stages of Change Theory (SCT) to address and better understand several problematic behaviours, such as smoking, unhealthy diet, insufficient exercise, poor stress management, poor medication adherence, bullying, alcohol 
abuse, domestic violence, substance abuse, delinquency, obesity, unplanned pregnancy and smoking while pregnant (Hall \& Rossi, 2008). The SCT is also known as the Transtheoretical model, and these terms have been used interchangeably in previous studies (Harris \& Cole, 2007; Slater, 1999). Social marketers apply the SCT to improve the welfare of individuals and society. A discussion of the SCT follows.

This theory was developed by Prochaska and DiClemente (1983), who argue that behaviour change is a process rather than a single step. Behaviour change involves several steps, so people require time to move along these steps. Thus, behaviour change is a time-consuming endeavour. This theory is used to explain how close the clients are to a new behaviour. Prochaska and DiClemente (1983) propose five stages of behavioural change or behavioural development: pre-contemplation, contemplation, preparation, action and maintenance. These theoretical stages are illustrated in Figure 1 and discussed below.

\section{Figure 1- The stages of change theory}

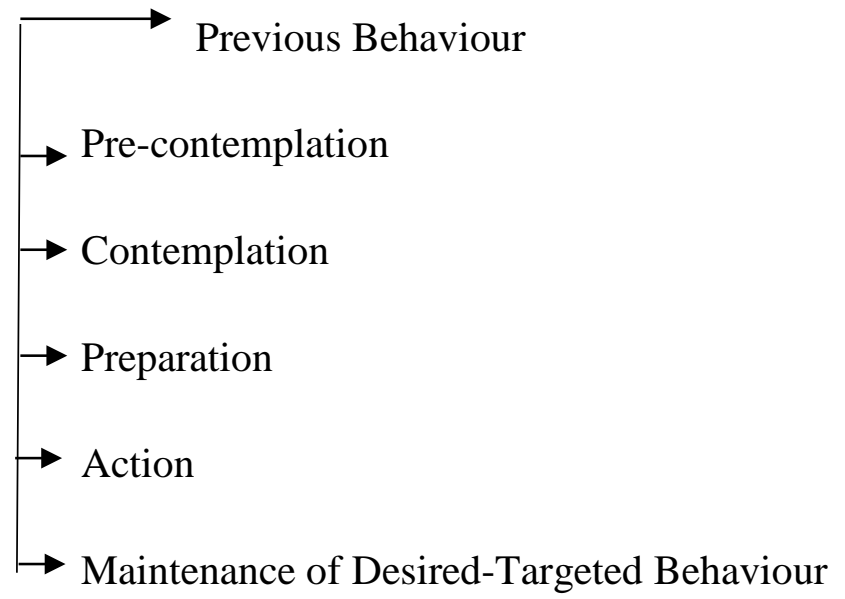

Source: Tung et al. (2010), Ferrer et al. (2009), Jebarajakirthy and Thaichon (2015) 
Figure 1 is the illustration of the SCT, which demonstrates that behavioural change comprises five stages: pre-contemplation, contemplation, preparation, action and maintenance. A discussion of each of these stages follows.

Pre-contemplation stage—Prochaska and DiClemente (1983) suggest that clients at the precontemplation stage would make little effort to adopt the new behaviour. As suggested by Prochaska, Redding, and Evers (2008), individuals associated with this stage are inadequately informed about the target behaviour and have a lack of knowledge of the behaviour. Consequently, at this stage, people are not interested in adopting the new behaviour, and would not think of progressing towards the behaviour (Andreasen, 2006).

Contemplation stage - at this stage, people are aware of the pros and cons of a target behaviour and as a consequence, they evaluate the behaviour (Prochaska et al., 1994). Andreasen (2006) suggests that generally people evaluate the costs and benefits associated with adopting a behaviour, which contributes to forming desires or a lack of interest relating to the target behaviour. Additionally, as highlighted by Andreasen (2006), at this stage, people can examine their confidence in adopting a given behaviour, thus enhancing their perceived behavioural control. Individuals at this stage start thinking about the target behaviour, which contributes to their developing a favourable "mindset” relating to this behaviour (Andreasen, 2006).

Preparation stage — Prochaska et al. (2008) suggest that at this stage, individuals intend to adopt the target behaviour and develop plans for taking that step (Prochaska et al., 2008; Prochaska et al., 1994). Other researchers agree with this view and remark that this stage is an intentional planning stage (Chapman-Novakofski \& Karduck, 2005; Hall \& Rossi, 2008; Spencer, Adams, Malone, Roy, \& Yost, 2006). 
Action stage - from the preparation stage, people progress towards the action stage where they convert their intentions and plans into practice. While people are at this stage, they modify their existing behaviour and carry out activities relating to the new target behaviour (Prochaska et al., 2008; Prochaska et al., 1994).

Maintenance stage-individuals who continue to practise the adopted target behaviour without relapse reach the maintenance stage. That is, individuals at this stage sustain their behavioural change. Prochaska et al. (2008) suggest that individuals at the maintenance stage have more confidence in successfully executing the target behaviour than those at the action stage. That is, as people continue to practise the new behaviour, their confidence in overcoming barriers to exercising the behaviour grows (Marshall \& Biddle, 2001).

It has been suggested that individuals at the maintenance stage require conditions and situations which prevent them from returning to the previous stages or completely giving up their adopted behaviours (Prochaska et al., 2008). To reduce the chance of this happening, researchers recommend that individuals need to be provided with opportunities to continue to learn about the adopted behaviours (Andreasen, 2002, 2006; Prochaska et al., 2008). So, at this stage, individuals require continuous knowledge and awareness of the adopted behaviour. For example, if a group of a target audience gives up smoking, they need to be continuously made aware of the adverse effects of smoking and the benefits of non-smoking, so that they do not smoke again. Also, because of this continuous learning, the group of new non-smokers would have stronger positive attitudes towards their adopted behaviour (James O Prochaska \& DiClemente, 1991).

\subsection{Rationale of using the SCT for understanding and encouraging condom usage}

Social marketing researchers and practitioners apply the SCT to understand and encourage various behaviours, such as healthy diet and non-smoking (Di Noia, Contento, \& Prochaska, 
2008; Hall \& Rossi, 2008; Mendes, 2013). The SCT is predominantly used in the Social marketing field to study and enhance clinical and health-related behaviours (Hastings, 2007). The founders of this theory, Prochaska and DiClemente (1983), suggest that this theory needs to be applied to encourage behavioural change in various contexts and among various groups of people. This indicates that the SCT is relevant to this study of condom use among Thai male sex workers.

This theory allows clients or target audiences to be segmented into behavioural stages (Andreasen, 2006; Hastings, 2007), based on the internal processes relating to behavioural adaptation, such as knowledge acquisition, the formation of attitudes and perceived behavioural control and the development of intention. Consequently, appropriate intervention programs can be designed to help usher them onto the next stage of the target behaviour. Intervention strategies normally differ across the different stages of behavioural change. For example, if clients are found to be at the pre-contemplation stage, their awareness of the target behaviour needs to be raised. If they are at the intention stage, they require action-oriented training to convert their plans about behavioural adoption into practice (Lyons, Swindler, \& Offner, 2009).

Based on this theory, it has been suggested that people differ in their readiness to adopt condom usage (Wei-Chen Tung, Lu, \& Cook, 2010). That is, condom usage behaviour can be divided into stages. Noar, Crosby, Benac, Snow, and Troutman (2011) and Grossman et al. (2008) suggest that attitudes, norms, confidence and ability relating to condom use differ across the stages of condom usage adaptation. Also, factors affecting condom usage can differ across the stages of behavioural adaptation (condom use adaption) (Noar et al., 2011). Hence, different intervention strategies would be required for those at the different stages of condom usage behaviour. For example, interventions for an individual who has no intention to use condoms would involve quite different strategies from those designed for an individual with strong intentions to use condoms but a lack of specific abilities for doing so. 
Although the SCT has been applied for investigating condom usage, it has been suggested that this theory does not take into consideration the norms and influence of others which can also impact one’s decision to use condoms (Arden \& Armitage, 2008; Noar et al., 2011; Pallonen, Williams, Timpson, Bowen, \& Ross, 2008). Sex involves at least two people, so the norms of sexual partners need to be taken into consideration (Pallonen et al., 2008). TPB considers the effects of norms (subjective norms), but it suffers from some other weaknesses which have been previously explained under the section titled "2.3 Criticisms of using TPB for understanding behavioural change". Therefore, this study proposes an alternative theoretical framework based on the underpinnings of both the SCT and TPB to encourage condom usage.

\subsection{The rationale of combining both TPB and SCT}

The TPB and SCT have been traditionally applied to design intervention programs targeting at behavioural change (Luca \& Suggs, 2013). Each of these two theories have been discussed previously. It is important to note each of these theories have exposed to weaknesses. The TPB explains the determinants of behavioural change intention, however, it does not show the staged transition of behavioural change (Armitage \& Talibudeen, 2010). It attempts to identify the psychological determinants of behavioural change intention and then combine these determinants in a single prediction equation (Callaghan, Khalil, \& Morres, 2010). That is, it does not show how the behaviour change occurs as a process, or at stages. Therefore, the TPB is not appropriate to use in longitudinal studies or to design longitudinal-based intervention programs (Sniehotta et al., 2014). As a consequence of this limitation, a permanent change in a behaviour cannot be observed using the TPB (Glanz \& Bishop, 2010).

On the other hand, the SCT shows the behaviour change as a process. However, it is not clear enough in showing the determinants of behavioural change. The SCT does not have 
informative and solid behavioural change determinants, such as subjective norms or behavioural intention. Therefore, SCT-based intervention programs cannot give solid recommendations to enhance behavioural change (Armitage, Sheeran, Conner, \& Arden, 2004; Pallonen et al., 2008). Researchers suggest behavioural change determinants proposed in the TPB can be incorporated into the SCT, and the change in these constructs can be examined across the stages of the behavioural adaptation (Armitage et al., 2004; Courneya, Plotnikoff, Hotz, \& Birkett, 2001). For example, in the combined application of TPB and SCT, changes to attitudes, perceived behavioural control, subjective norms and behavioural intention can be examined between the stages. Furthermore, sound intervention measures can be designed to address insufficiencies in the determinants at the specific stages (Brouwer et al., 2009).

Another rationale for combining SCT with TPB is that the SCT incorporates the knowledge and awareness of a new targeted behaviour, which suitably addresses the main shortcoming of the TPB. As previously discussed, the TPB does not pay adequate attention to individuals' knowledge of a certain behaviour. The SCT postulates that the knowledge of the new behaviour increases as people adopt and continue to practise the behaviour (Wei-Chen Tung et al., 2010). Knowledge of the new targeted behaviour determines audience readiness to adopt the behaviour. In studies that used the SCT, the knowledge has been incorporated as a determinant of behavioural adaptation (Hassan Eftekhar MD, 2010; Kim, 2007) and special emphasis has been placed on raising the knowledge and awareness of the new behaviour (Di Noia et al., 2008; Shockey \& Seiling, 2004). That is, the audience's knowledge of the new behaviour determines both their current stage of behavioural adaptation, and assistance and intervention required to move them onto the following stages of the behavioural adaptation. Knowledge of new behaviour generates interests and confidence in adopting the behaviour (Kwon et al., 2008). It plays an important role in moving an audience from the initial stages of behavioural 
change (pre-contemplation and contemplation) to the middle and latter stages of behavioural change (preparation, action and maintenance) (Tucker, Snelling, \& Adams, 2002). Therefore, this study combines TPB with SCT to develop a comprehensive framework to design behavioural change interventions.

The development of this framework is discussed in the following section. As this framework was based on the TPB and SCT literature, it can contribute to designing theoretically-based intervention strategies.

\subsection{The development of comprehensive framework for promoting condom usage: Combining the TPB and the SCT}

Using the underpinnings of the TPB and SCT, a new framework is developed to effectively promote condom usage to male sex workers in Thailand. The development of this framework is explained in detail below.

If people do not have the knowledge and awareness of a new behaviour, they will be unlikely to have any interest in adopting it (Andreasen, 2006; Olson \& Zanna, 1993). Similarly, those who are unaware of condom use and its benefits would be unlikely to be interested in adopting safe sex behaviours, indicating that they would be in the pre-contemplation stage. They might have negative attitudes towards and poor confidence in, using condoms. For example, due to their lack of awareness of condom use and its benefits, some individuals would perceive that 
condoms might reduce sexual pleasure. They would also anticipate many barriers to condom usage.

Behavioural change normally begins when people become aware of new behaviour, its benefits and consequences (Icek Ajzen, Joyce, Sheikh, \& Cote, 2011). Those who become aware of the availability, usage and the benefits of condoms, either form positive attitudes or alter their negative attitudes towards condom use. Also, becoming aware of and forming positive attitudes towards condom use can contribute to a confidence in their abilities to use condoms. They will also have confidence in negotiating condom use with their sexual partner. That is, at this stage, they gain perceived behavioural control to use condoms. Additionally, they would be influenced by others, namely their referent people to use condoms. Andreasen (2006) highlights that people located at the contemplation stage are influenced by others, namely their referent people. This influence is similar to subjective norms referred to in the TPB literature. Both gaining knowledge and forming attitudes, subjective norms and perceived behavioural control contribute to developing a mindset for condoms use. This "mindset" development is a major change required to take place at the contemplation stage (Andreasen, 2006). Thus, clients experiencing changes, such as knowledge, attitudes, perceived behavioural and subjective norms, would be likely be situated in the contemplation stage (Andreasen, 2002, 2006).

Subsequent to the contemplation stage, clients develop intentions and plans to adopt targeted behaviour which is similar to changes associated with the preparation stage (ChapmanNovakofski \& Karduck, 2005; Hall \& Rossi, 2008; Prochaska et al., 2008; Prochaska et al., 1994). Similarly, male sex workers who have formed the intention to use condoms would likely be in the preparation stage. At this stage, they intend to use condoms, and make decisions and 
plans about when, where and with whom to use condoms. They also intend to negotiate their intentions for condom usage with their sexual partners.

In this respect, people converting their intentions into practice and those who started using condoms within the last six months will be at the action stage (Prochaska et al., 2008). For example, those who started using condoms recently would be at this stage. These individuals would require greater levels of assistance in overcoming possible barriers associated with condom use until this behaviour becomes their usual practice.

Clients continually using condoms for more than six months are confident in overcoming barriers to using condoms. Hence, they are generally able to continue the behaviour and be regarded at the maintenance stage of condom use (Marshall \& Biddle, 2001). At this stage, people grow in their knowledge of and confidence in practising this behaviour, which prevents them from giving up the adopted behaviour. Similarly, those at this stage of condom use, would have greater awareness, and stronger attitudes and confidence relating to condom use. Moreover, they would also enhance their skills in continuing to use condoms.

It has been indicated that an audience at the maintenance stage can sometimes relapse to the previous stages. That is, although people have reached the maintenance stage, it is not certain that they have completely terminated the problematic behaviour (Donovan \& Henley, 2010). The audience at the maintenance stage tend to the face temptation to relapse to the previous stages which is the main barrier encountered at the maintenance stage. To avoid their relapse and overcome temptation, continuous monitoring, awareness building, coping strategies and assistance programs are needed (Simpson, Suarez, \& Connolly, 2012). Similarly, the individuals who have arrived at the maintenance stage of condom use are sometimes tempted 
to relapse to the previous stages of condom use mainly because of a sexual partner's pressure. Hence, this audience should be given continuous access to confidence-building programs, skills enhancement programs, medical assistance and free condoms (Grossman et al., 2008).

Based on the preceding discussion, a framework has been developed for effectively encouraging condom use to sex workers (Please see Figure 2). This model depicts the stages of and possible outcomes relating to adopting condom use. This framework has been developed from the underpinnings of both the TPB and the SCT. 
Figure 2-The development of new framework for understanding and encouraging condom usage

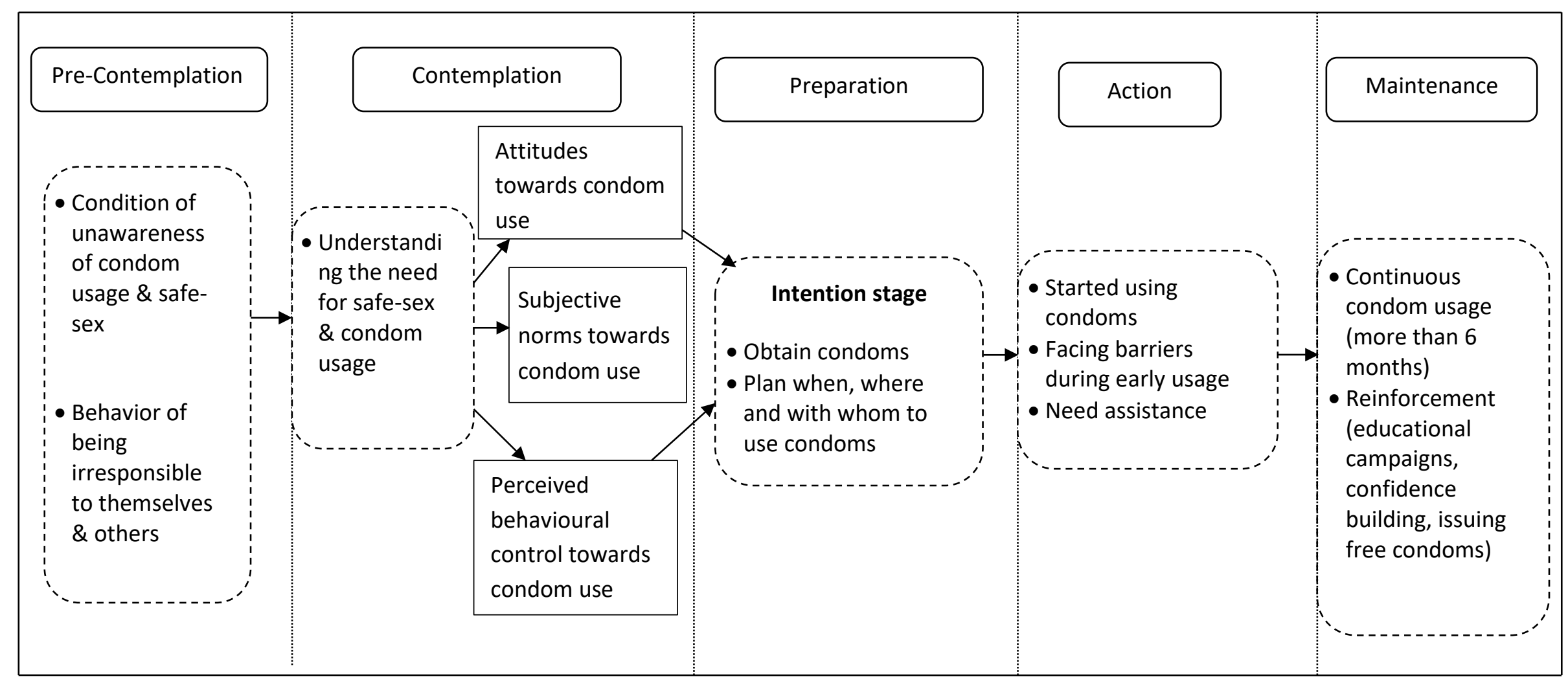




\section{Implementing this model (Designing intervention programs)}

This framework is supported by theories. Since it has been derived from the underpinnings of both the SCT and the TPB, the framework can contribute to designing theoretically sound intervention strategies. Already the SCT has been widely applied for promoting condom usage and safer sex practices (Pallonen, Timpson, Williams, \& Ross, 2009; Wei-Chen Tung et al., 2010). To develop this framework, the SCT is slightly modified by incorporating the underpinnings of the TPB. This indicates that the framework can be easily implemented. To demonstrate how it can be implemented, take for example the sex workers in Pattaya city, one of the popular tourist cities in Thailand.

It will be communicated via mass media and social media sites that a program is available to assist male sex workers in Pattaya city, with all male sex workers extended an invitation to an interview. Referrals will also be used to contact male sex workers. That is, participating male sex workers will be asked to connect the interviewers with other male sex workers. Referrals have been widely used to identify and contact participants for studies relating to hidden and elusive populations and sexual practices (Gullette, Wright, Booth, Feldman, \& Stewart, 2009; Pallonen et al., 2008; Pallonen et al., 2009).

The venue of the interview will be indicated in the communication, and it will also be stipulated that it will be a confidential one-to-one interview. This style of structured interview will be organized with each willing male sex worker and administered with the utmost confidentiality. The sex workers' participation in this interview will be completely voluntary. Prior to obtaining interested respondents' consent for participation in the program, the purpose and voluntary nature of the program will be explained. Each respondent will be interviewed based on the interview questionnaire shown in Table 1 which has been carefully prepared based on the previous literature. 
Table 1

\section{Questions to identify the stages of condom use adaptation}

I have no knowledge or interest in using condoms - pre-contemplation stage

I am interested in using condoms - contemplation stage

I have developed plans and intentions to, and made decisions to, use condoms in the near future (when, where and with whom to use condoms)- Preparation stage

I have begun to use condoms every time I have sex, only within the last six months - action stage

I have been using condoms every time I have sex, for longer than the last six months -

maintenance stage

\section{Perceived benefits}

1. I would feel more responsible

2. I would be safe from getting a sexually transmitted disease

3. It protects me and my clients

4. I would feel guilty if my clients and I didn’t use a condom

\section{Perceived barriers}

1. It makes sex feel unnatural

2. It would be too much trouble

3. My clients would be angry

4. I would have to rely on my clients' cooperation

5. My clients would think that I do not trust him/her

6. Sex doesn't feel as good when I use a condom

7. Condoms interrupt the flow of sex

8. Condoms make sex less exciting

\section{Self-efficacy}

1. I am confident that I would be able to use a condom every time I have sex with clients

2. It is easily available

3. I am confident that I will be able to carry a condom with me every time

4. I am confident that I would be able to use a condom when my clients pressure me to take a chance without it

Respondents will be asked to tick only one most relevant option out of the five relating to the stages of condom use adaptation. This will enable the respondents to be classified into the five stages of condom usage. Pros (perceived advantages) and cons (perceived disadvantages) as 
well as self-efficacy or perceived behavioural control (individual's confidence in his or her ability to practise the behaviour) relating to adopting a new behaviour, are considered the dependent variables of SCT, which indicates these constructs change as people move along the stages of behavioural change (Erol \& Erdogan, 2008; Hassan Eftekhar MD, 2010; W-C Tung, Nguyen, \& Tran, 2008). Thus, they were also identified using the same interview questionnaire. A five-point Likert type scale anchored at one for "strongly disagree" and five for "strongly agree” can be used for items operationalizing these constructs. All the items used in the interview questionnaire were derived from the previous studies that used the SCT while investigating behavioural change (Arden \& Armitage, 2008; Grossman et al., 2008; Jebarajakirthy \& Thaichon, 2015; Taghdisi, 2010; Wei-Chen Tung et al., 2010). However, these items were modified to suit the purpose of this particular study. Their demographic factors, such as age, income, educational background, place of residence, marital status and their number of dependents, will also be identified using the interview questionnaire.

Once their current stage of condom use is identified, their magnitude of pros (positive attitudes) and cons (negative attitudes) and self-efficacy or perceived behavioural control relating to condom use can be identified at each stage. One-way ANOVA and its associated Tukey's posthoc test can be used for this analysis. Other studies that used the SCT have also used the same analytical techniques to determine audience's pros (positive attitudes) and cons (negative attitudes) as well as self-efficacy or perceived behavioural control at each stage of behavioural change. This analysis will enable the researchers to identify in which specific aspects the respondents require assistance relating to adopting condom usage. That is, in addition to identifying their current stage of condom usage, it can also be identified whether they lack awareness, positive attitudes, or the ability relating to adopting condom usage.

Next, an appropriate intervention program should be administered to respondents aimed at assisting them to move onto the next stage of condom use adaptation. This means that if they 
are in the pre-contemplation stage, they will be given the awareness of using condoms and safer sex. Likewise, for those at the contemplation stage, confidence building measures and incentives will be given, which will assist them in developing plans and intentions to adopt condom usage. Free condoms would be issued to those who have formed the intentions to use condoms, in order to convert their intentions into action. Continuous assistance and monitoring will be provided to those who have started using condoms recently (those at the action stage), which will assist them in continuing the behaviour.

In one month's time, each respondent (participant) will be again invited along to the next phase of the program where they will be interviewed based on the same instrument. Following this interview, their current stage of condom usage will be determined and it will be assessed whether they have progressed in their condom usage behaviour. That is, it would be assessed whether participants have moved onto the next stage of condom usage adaptation. Pros (positive attitudes) and cons (negative attitudes) and self-efficacy or perceived behavioural control relating to condom use will also be assessed again, which will help determine their progress in those aspects. Following this, appropriate intervention programs will be administered. These steps will be repeated for each participant on a regular time basis (for example, each month) until the participant permanently adopts condom use (maintenance stage). We recommend continuing this program for about six to 12 months since other longitudinal studies that used the SCT based intervention programs typically varied between three to 12 months (Callaghan et al., 2010; Erol \& Erdogan, 2008; Grossman et al., 2008). Repeated follow-ups have also been carried out in previous studies applying the SCT for designing behavioural intervention (Erol \& Erdogan, 2008; Ferrer et al., 2009).

\section{Academic implications}


This research proposes a unique framework by combining the underpinnings of the Theory of Planned Behaviour with the Stages of Change Theory to encourage condom usage to male sex workers. Thus, this study contributes to filling a gap in the literature. It extends the applications of social marketing theories and interventions to vulnerable men in Thailand and suggests a likely relationship between the TPB and the SCT. This means that behavioural determinants articulated in the TPB - namely attitudes, subjective norms and perceived behavioural control - can be related to the behavioural changes taking place at the contemplation stage, and the formation of intentions can be linked to the preparation stage of the SCT. Thus, there appear to be relationships between these two theories, which is an additional theoretical contribution of this study. This suggests that rather than applying these theories individually to make a behavioural change or to investigate a given behaviour, applying a combination of these theories can produce greater results. Hence, this study can contribute to informing social marketers. However, testing this model in different settings would be of use in confirming this theoretical contribution. Finally, this study has implications for future researchers, which will make a useful contribution to knowledge in the future.

\section{Practical implications}

Besides suggesting some academic implications, this study will be useful for social marketers, policy makers and non-governmental organizations in developing strategies to promote condom use and safe sex practices in prominent tourist destinations of Thailand, where sex tourism is popular. This model also proposes a mechanism for segmenting male sex workers based on their condom usage practices. As such, social marketers can use this mechanism in similar contexts. This framework suggests what specific changes take place and what factors determine condom use adaptation, at each stage. These suggestions would be of use to social marketers in designing differing intervention programs based on the stage at which male sex workers currently lie in relation to condom use. For example, for those at the pre-contemplation stage of condom use, the most appropriate intervention would be to raise the awareness of 
condom use and its benefits. For those at the action and maintenance stages, the intervention programs could be designed to build their confidence in continuing to use condoms and to enhance their skills to use condoms. We have also made some recommendations to design and implement interventions based on the framework. These will be of use to social marketers in determining how the demographic factors of clients, such as age, gender, and income, differ across the stages of behavioural adaption (condom use). Hence, intervention programs can be tailor-made to suit their demographic profiles.

\section{Directions for future research}

This study opens avenues for future research. Firstly, in addition to the changes we suggest at each stage of behavioural change, there might be some other changes that can possibly take place at each stage. For example, from a meta-analysis of 142 research studies which applied the TPB, Armitage and Conner (2001) showed that an average of only $40 \%$ variance in behavioural intentions can be predicted by the three determinants conceptualized in the TPB. They suggested that self-identity, past behaviour, moral norms and anticipated emotions can be considered additional determinants of behavioural intentions. Thus, future researchers can incorporate these determinants into this model, and investigate how these determinants change across the stages.

While we have developed an interview questionnaire, future researchers can improve on it by adding and refining the questions. These changes can make the instrument relevant to other contexts. In addition to developing guidelines for implementing this model and attaching an interview questionnaire, we have suggested some basic analytical techniques for empirically testing this framework. Future researchers can follow these analytical steps to analyse the data and also perform further in-depth analyses as appropriate to the study. 
Although this framework suggests useful implications for promoting condom usage to male sex workers in Thailand, it is grounded in the theories. That is, our framework is derived from theories (the SCT and the TPB) which have been tested and applied in various contexts (Armitage and Conner, 2001, Luca and Suggs, 2013, Armitage, 2009). Therefore, our model can be tested and applied in other contexts for promoting condom use to male sex workers. Future researchers can also expand, improve and modify our model based on cultural and contextual factors as appropriate. This model can also be applied for encouraging condom use to female sex workers. Additionally, this study combines both the TPB and the SCT, and suggests a new framework for investigating behavioural change. Therefore, the conceptual model proposed in this study can potentially be applied for changing other behaviours of interest to social marketers, such as smoking, binge driving and unhealthy dietary practices.

\section{References}

Ajzen, I. (1991). The theory of planned behavior. Organizational behavior and human decision processes, 50(2), 179-211.

Ajzen, I., \& Fishbein, M. (1980). Understanding attitudes and predicting social behaviour. Englewood-Cliffs, NJ: Prentice-Hall.

Ajzen, I., Joyce, N., Sheikh, S., \& Cote, N. G. (2011). Knowledge and the prediction of behavior: The role of information accuracy in the theory of planned behavior. Basic and Applied Social Psychology, 33(2), 101-117.

Ananth, P., \& Koopman, C. (2003). HIV/AIDS knowledge, beliefs, and behavior among women of childbearing age in India. AIDS Education and Prevention, 15(6), 529-546.

Andreasen, A. R. (2002). Marketing Social Marketing in the Social Change Marketplace. Journal of Public Policy \& Marketing, 21(1), 3-13.

Andreasen, A. R. (2006). Social Marketing in the 21st Century. London: SAGE Publications.

Arden, M. A., \& Armitage, C. J. (2008). Predicting and explaining transtheoretical model stage transitions in relation to condom-carrying behaviour. British journal of health psychology, 13(4), 719-735.

Armitage, C. J., \& Conner, M. (2001). Efficacy of the Theory of Planned Behaviour: A metaanalytic review. British Journal of Social Psychology, 40(4), 471.

Armitage, C. J., Sheeran, P., Conner, M., \& Arden, M. A. (2004). Stages of change or changes of stage? Predicting transitions in transtheoretical model stages in relation to healthy food choice. Journal of consulting and clinical psychology, 72(3), 491.

Armitage, C. J. (2009). Is there utility in the transtheoretical model? British journal of health psychology, 14(2), 195-210. 
Armitage, C. J., \& Talibudeen, L. (2010). Test of a brief theory of planned behaviour-based intervention to promote adolescent safe sex intentions. British Journal of Psychology, 101(1), 155-172.

Australian Broadcasting Corporation. (2013). HIV-AIDS biggest health risk in Thailand. Australian Network News. Retrieved from http://www.abc.net.au/news/2013-0821/an-hiv-aids-still-biggest-health-risk-in-thailand/4902058.

Bangkok Post. (2012). Thailand tourism: New record set in 2012 Retrieved from http://www.bangkokpost.com/learning/learning-from-news/333064/thailand-tourismnew-record-set-in-2012.

Brouwer, S., Krol, B., Reneman, M. F., Bültmann, U., Franche, R.-L., van der Klink, J. J., \& Groothoff, J. W. (2009). Behavioral determinants as predictors of return to work after long-term sickness absence: an application of the theory of planned behavior. Journal of occupational rehabilitation, 19(2), 166-174.

Buckingham, R. W., Moraros, J., Bird, Y., Meister, E., \& Webb, N. C. (2005). Factors associated with condom use among brothel-based female sex workers in Thailand. AIDS care, 17(5), 640-647.

Callaghan, P., Khalil, E., \& Morres, I. (2010). A prospective evaluation of the Transtheoretical Model of Change applied to exercise in young people. International journal of nursing studies, 47(1), 3-12.

Carmack, C. C., \& Lewis-Moss, R. K. (2009). Examining the theory of planned behavior applied to condom use: The effect-indicator vs. causal-indicator models. The journal of primary prevention, 30(6), 659-676.

Chapman-Novakofski, K., \& Karduck, J. (2005). Improvement in Knowledge, Social Cognitive Theory Variables, and Movement through Stages of Change after a Community-Based Diabetes Education Program. Journal of the American Dietetic Association, 105(10), 1613-1616.

Chatzisarantis, N. L., \& Hagger, M. S. (2005). Effects of a brief intervention based on the theory of planned behavior on leisure-time physical activity participation. Journal of Sport and Exercise Psychology, 27(4), 470.

Chemnasiri, T., Netwong, T., Visarutratana, S., Varangrat, A., Li, A., Phanuphak, P., van Griensven, F. (2010). Inconsistent condom use among young men who have sex with men, male sex workers, and transgenders in Thailand. AIDS Education \& Prevention, 22(2), 100-109.

Courneya, K. S., Plotnikoff, R. C., Hotz, S. B., \& Birkett, N. J. (2001). Predicting exercise stage transitions over two consecutive 6-month periods: A test of the theory of planned behaviour in a population-based sample. British journal of health psychology, 6(2), 135-150.

Di Noia, J., Contento, I. R., \& Prochaska, J. O. (2008). Computer-mediated intervention tailored on transtheoretical model stages and processes of change increases fruit and vegetable consumption among urban African-American adolescents. American Journal of Health Promotion, 22(5), 336-341.

Donovan, R., \& Henley, N. (2010). Principles and Practice of Social Marketing: An International Perspective. Cambridge: Cambridge University Press.

Donovan, R. J., \& Henley, N. R. (2003). Social Marketing: Principles and Practice. Melbourne: IP Communications Pty.

Erol, S., \& Erdogan, S. (2008). Application of a stage based motivational interviewing approach to adolescent smoking cessation: the Transtheoretical Model-based study. Patient Education and Counseling, 72(1), 42-48. 
Evans, C., \& Lambert, H. (2008). The limits of behaviour change theory: condom use and contexts of HIV risk in the Kolkata sex industry. Culture, health \& sexuality, 10(1), 2741.

Ferrer, R. A., Amico, K. R., Bryan, A., Fisher, W. A., Cornman, D. H., Kiene, S. M., \& Fisher, J. D. (2009). Accuracy of the stages of change algorithm: Sexual risk reported in the maintenance stage of change. Prevention Science, 10(1), 13-21.

Fontanet, A. L., Saba, J., Chandelying, V., Sakondhavat, C., Bhiraleus, P., Rugpao, S., Dally, L. (1998). Protection against sexually transmitted diseases by granting sex workers in Thailand the choice of using the male or female condom: results from a randomized controlled trial. Aids, 12(14), 1851-1859.

Ford, N., \& Koetsawang, S. (1999). A pragmatic intervention to promote condom use by female sex workers in Thailand. Bulletin of the World Health Organization, 77(11), 888.

Garcia-Retamero, R., \& Cokely, E. T. (2011). Effective communication of risks to young adults: using message framing and visual aids to increase condom use and STD screening. Journal of Experimental Psychology: Applied, 17(3), 270.

Glanz, K., \& Bishop, D. B. (2010). The role of behavioral science theory in development and implementation of public health interventions. Annual review of public health, 31, 399418.

Grossman, C., Hadley, W., Brown, L. K., Houck, C. D., Peters, A., Tolou-Shams, M., \& Group, P. S. S. (2008). Adolescent sexual risk: Factors predicting condom use across the stages of change. AIDS and Behavior, 12(6), 913-922.

Gu, J., Lau, J. T., Chen, X., Liu, C., Liu, J., Chen, H., Li, Z. (2009). Using the Theory of Planned Behavior to investigate condom use behaviors among female injecting drug users who are also sex workers in China. AIDS care, 21(8), 967-975.

Guadamuz, T. E., Kunawararak, P., Beyrer, C., Pumpaisanchai, J., Wei, C., \& Celentano, D. D. (2010). HIV prevalence, sexual and behavioral correlates among Shan, Hill tribe, and Thai male sex workers in Northern Thailand. AIDS care, 22(5), 597-605.

Gullette, D. L., Wright, P. B., Booth, B. M., Feldman, Z., \& Stewart, K. E. (2009). Stages of change, decisional balance, and self-efficacy in condom use among rural AfricanAmerican stimulant users. Journal of the Association of Nurses in AIDS Care, 20(6), 428-441.

Hall, K. L., \& Rossi, J. S. (2008). Meta-analytic examination of the strong and weak principles across 48 health behaviors. Preventive Medicine: An International Journal Devoted to Practice and Theory, 46(3), 266-274.

Harris, S. G., \& Cole, M. S. (2007). A stages of change perspective on managers' motivation to learn in a leadership development context. Journal of Organizational Change Management, 20(6), 774-793.

Hassan Eftekhar MD, M. (2010). Physical activity among a sample of Iranians aged over 60 years: an application of the transtheoretical model. Archives of Iranian medicine, 13(6), 528.

Hastings, G. (2007). Social marketing: Why should the devil have all the best tunes? Oxford Elsevier Ltd.

Janepanish, P., Dancy, B. L., \& Park, C. (2011). Consistent condom use among Thai heterosexual adult males in Bangkok, Thailand. AIDS care, 23(4), 460-466.

Jebarajakirthy, C., \& Thaichon, P. (2015). A conceptual framework for understanding and developing entrepreneurial behaviour: implications for social marketers. International Journal of Nonprofit and Voluntary Sector Marketing, 20(4), 299-311. 
Kim, Y.-H. (2007). Application of the transtheoretical model to identify psychological constructs influencing exercise behavior: a questionnaire survey. International journal of nursing studies, 44(6), 936-944.

Kwon, Y. M., Yeun, E. J., Kim, H. Y., Youn, M. S., Cho, J. Y., \& Lee, H. J. (2008). Application of the transtheoretical model to identify aspects influencing condom use among Korean college students. Western journal of nursing research, 30(8), 991-1004.

Luca, N. R., \& Suggs, L. S. (2013). Theory and model use in social marketing health interventions. Journal of health communication, 18(1), 20-40.

Lyons, J. B., Swindler, S. D., \& Offner, A. (2009). The impact of leadership on change readiness in the US military. Journal of Change Management, 9(4), 459-475.

Marshall, S. J., \& Biddle, S. J. H. (2001). The Transtheoretical Model of Behavior Change: A Meta-Analysis of Applications to Physical Activity and Exercise. Annals of Behavioral Medicine, 23(4), 229-246.

Mausbach, B. T., Semple, S. J., Strathdee, S. A., \& Patterson, T. L. (2009). Predictors of safer sex intentions and protected sex among heterosexual HIV-negative methamphetamine users: An expanded model of the theory of planned behavior. AIDS care, 21(1), 17-24.

McEachan, R. R. C., Conner, M., Taylor, N. J., \& Lawton, R. J. (2011). Prospective prediction of health-related behaviours with the Theory of Planned Behaviour: a meta-analysis. Health Psychology Review, 5(2), 97-144.

Mendes, E. (2013). An Application of the Transtheoretical Model to Becoming Vegan. Social work in public health, 28(2), 142-149.

Montano, D. E., \& Kasprzyk, D. (2008). Theory of reasoned action, theory of planned behavior, and the integrated behavioral model. In K. Glanz, B. K. Rimer, \& K. Viswanath (Eds.), Health behavior and health education: Theory, research, and practice (4 ed., pp. 6795). San Francisco Jossey-Bass.

Noar, S. M., Crosby, R., Benac, C., Snow, G., \& Troutman, A. (2011). Application of the attitude-social influence-efficacy model to condom use among African-American STD clinic patients: implications for tailored health communication. AIDS and Behavior, 15(5), 1045-1057.

Olson, J. M., \& Zanna, M. P. (1993). Attitudes and attitude change. Annual review of psychology, 44(1), 117-154.

Ouyyanont, P. (2001). The Vietnam War and Tourism in Bangkok's Development, 1960-70. The Southeast Asian studies, 39(2), 157-187.

Pallonen, U., Williams, M., Timpson, S., Bowen, A., \& Ross, M. (2008). Personal and partner measures in stages of consistent condom use among African-American heterosexual crack cocaine smokers. AIDS care, 20(2), 205-213.

Pallonen, U. E., Timpson, S. C., Williams, M. L., \& Ross, M. W. (2009). Stages of consistent condom use, partner intimacy, condom use attitude, and self-efficacy in AfricanAmerican crack cocaine users. Archives of sexual behavior, 38(1), 149-158.

Peattie, K., \& Peattie, S. (2009). Social marketing: a pathway to consumption reduction? Journal of business research, 62(2), 260-268.

Prochaska, J. O., \& DiClemente, C. C. (1983). Stages and processes of self-change of smoking: Toward an integrative model of change. Journal of Consulting and Clinical Psychology, 51(3), 390-395.

Prochaska, J. O., \& DiClemente, C. C. (1991). Stages of change in the modification of problem behaviors. Progress in behavior modification, 28, 183-218.

Prochaska, J. O., Redding, C. A., \& Evers, K. E. (2008). The transtheoretical model and stages of exchange. In K. Glanz, B. K. Rimer, \& K. Viswanath (Eds.), Health behavior and health education: theory, research, and practice (4th ed., pp. 97-121). San Francisco Jossey-Bass. 
Prochaska, J. O., Velicer, W. F., Rossi, J. S., Goldstein, M. G., Marcus, B. H., Rakowski, W., Rossi, S. R. (1994). Stages of change and decisional balance for 12 problem behaviors. Health Psychology, 13(1), 39-46.

Schaalma, H., Aarø, L. E., Flisher, A. J., Mathews, C., Kaaya, S., Onya, H., Klepp, K.-I. (2009). Correlates of intention to use condoms among Sub-Saharan African youth: the applicability of the theory of planned behaviour. Scandinavian journal of public health, 37(2 suppl), 87-91.

Shockey, S. S., \& Seiling, S. B. (2004). Moving into action: Application of the transtheoretical model of behavior change to financial education. Journal of Financial Counseling and Planning, 15(1), 41.

Simpson, D., Suarez, L., \& Connolly, S. (2012). Treatment and outcomes for anxiety disorders among children and adolescents: A review of coping strategies and parental behaviors. Current psychiatry reports, 14(2), 87-95.

Slater, M. D. (1999). Integrating application of media effects, persuasion, and behavior change theories to communication campaigns: A stages-of-change framework. Health Communication, 11(4), 335-354.

Sniehotta, F. F. (2009). Towards a theory of intentional behaviour change: Plans, planning, and self-regulation. British journal of health psychology, 14(2), 261-273.

Sniehotta, F. F., Presseau, J., \& Araújo-Soares, V. (2014). Time to retire the theory of planned behaviour. Health Psychology Review, 8(1), 1-7.

Spencer, L., Adams, T. B., Malone, S., Roy, L., \& Yost, E. (2006). Applying the Transtheoretical Model to Exercise: A Systematic and Comprehensive Review of the Literature. Health Promotion Practice, 7(4), 428-443.

Taghdisi, M. H. (2010). Physical activity among a sample of Iranians aged over 60 years: an application of the transtheoretical model. Archives of Iranian medicine, 13(6), 528.

Toledo, C. A., Varangrat, A., Wimolsate, W., Chemnasiri, T., Phanuphak, P., Kalayil, E. J., van Griensven, F. (2010). Examining HIV infection among male sex workers in Bangkok, Thailand: a comparison of participants recruited at entertainment and street venues. AIDS Education and Prevention, 22(4), 299.

Tucker, L., Snelling, A. M., \& Adams, T. B. (2002). Development and validation of a stages of change algorithm for calcium intake for college female students. Journal of the American College of Nutrition, 21(6), 530-535.

Tung, W. C., Lu, M., \& Cook, D. M. (2010). Condom use and stages of change among college students in Taiwan. Public health nursing, 27(6), 474-481.

Tung, W. C., Nguyen, D., \& Tran, D. (2008). Applying the transtheoretical model to cervical cancer screening in Vietnamese-American women. International Nursing Review, 55(1), 73-80.

UNGASS. (2012). Thailand: Global AIDS Response Country Progress Report, UNGASS. Retrieved from http://www.unaids.org/ en/dataanalysis/ knowyourresponse/ countryprogressreports/ 2012 countries/ce_TH_Narrative_Report[1].pdf.

United Nations Programme on HIV/AIDS. (2000). Evaluation of the 100\% Condom Programme in Thailand. Geneva, Switzerland: UNAIDS: United Nations Programme on HIV/AIDS.

Wawer, M. J., Podhisita, C., Kanungsukkasem, U., Pramualratana, A., \& McNamara, R. (1996). Origins and working conditions of female sex workers in urban Thailand: Consequences of social context for HIV transmission. Social Science \& Medicine, 42(3), 453-462. 